\title{
Biochemical profile of amniotic fluid for the assessment of fetal and renal development
}

F.R. Oliveira ${ }^{1}$, E.G. Barros ${ }^{2}$ and J.A. Magalhães ${ }^{1}$

\author{
'Divisão de Medicina Materno-Fetal, Departamento de O bstetrícia e Ginecologia, \\ and ${ }^{2}$ Divisão de Nefrologia, Departamento de Medicina Interna, \\ Hospital de Clínicas de Porto Alegre, Universidade Federal do Rio Grande do Sul, \\ Porto Alegre, RS, Brasil
}

\section{Correspondence}

F.R. Oliveira

Rua Dr. Florêncio Ygartua, 300/301

90430-010 Porto Alegre, RS

Brasil

Fax: +55-51-3222-9074

E-mail:

fernando@equipemedica.com.br

Received July 6, 2001

Accepted November 14, 2001

\section{Abstract}

Creatinine plays a key role in the function and maturation of fetal kidneys throughout pregnancy. It is important to identify other markers that may help in the diagnosis of renal dysfunction. Our aim was to determine the profile of and the correlation between biochemical markers to be used to assess renal function and maturation of the fetus in the amniotic fluid during pregnancy and to determine the distribution of normal values for creatinine, $\mathrm{N}$-acetyl- $\mathrm{B}-\mathrm{D}$-glucosaminidase (NAG), B2-microglobulin, glucose, urea, sodium, potassium, phosphorus, calcium, uric acid, albumin, and osmolality in three gestational age groups. This was a cross-section study that assessed 115 samples of amniotic fluid during three different periods of pregnancy, i.e., 13 to 20,27 to 34 , and 36 to 42 weeks. Concentrations of creatinine, NAG, urea, potassium and uric acid increased during pregnancy $(\mathrm{P}<0.05)$. $32-$ Microglobulin, glucose, sodium, phosphorus, calcium, and albumin concentration and osmolality decreased $(\mathrm{P}<0.05)$, whereas 32 -microglobulin, glucose and uric acid presented significant correlations with gestational age and creatinine, respectively $(r>0.6, \mathrm{P}<0.05)$. Urea, potassium and phosphorus showed mild correlations with both $(\mathrm{r}>0.5, \mathrm{P}<0.05)$. NAG, sodium, albumin and osmolality did not show significant correlations $(\mathrm{r}<0.5, \mathrm{P}<0.05)$. These tests confirmed the important role of creatinine in terms of correlation with gestational age. B2-Microglobulin, glucose and uric acid were significant as markers of function and maturation of fetal kidneys, whereas NAG did not demonstrate a useful role for the assessment of renal maturation.

\section{Introduction}

A normal volume of amniotic fluid was initially considered as the only index of fetal kidney development, but the origin and concentration of many biochemical substances later began to be investigated $(1,2)$. Many advances in diagnostic methods during the

\section{Key words}

- Fetal renal maturation

- Normal pregnancy

- Amniotic fluid

- Creatinine

- ß2-M icroglobulin

- Glucose

- Uric acid 
Grupe (4) and Shackelford et al. (5), the sonographic findings were not sufficient to assess renal function.

Analysis of creatinine and urea in amniotic fluid permits an evaluation of renal maturation and functionality throughout pregnancy (6-9). Creatinine values in the amniotic fluid that best represent fetal maturity are 1.5 to $2.0 \mathrm{mg} / \mathrm{dl}(6,10)$. A creatinine concentration of $1.75 \mathrm{mg} / \mathrm{dl}$ or more correlates significantly with a gestational age of 37 weeks or more (11). Other biochemical markers such as N-acetyl- $\beta$-D-glucosaminidase (NAG) (12) and B2-microglobulin (13) have been used as an index of renal maturity.

In cases of malformations such as obstructive uropathy, the concentrations of sodium, B2-microglobulin and the osmolality of the fetal urine are important to evaluate fetal impairment and the necessity of catheter placement (14). The aim of the present study was to determine amniotic fluid changes evaluated by biochemical renal markers in three gestational age groups of normal pregnancies.

\section{Patients and Methods}

In a cross-section study we selected 115 pregnant patients from the Hospital de Clínicas de Porto Alegre, from January 1998 to December 1999. The pregnant women were divided into groups corresponding to three different periods of pregnancy, i.e., 13 to 20 weeks (group 1), 27 to 34 weeks (group 2) and more than 36 weeks (group 3). Gestational age was determined on the basis of the last menstrual period and by timing sonograms. The amniotic fluid samples of group 1 were drawn by amniocentesis from pregnant women who were attended at Hospital de Clínicas de Porto Alegre for cytogenetic evaluation. Group 2 and 3 samples were drawn by amniocentesis from pregnant women who presented fetal risk or by cesarean section indicated only for obstetrical reasons.
The exclusion criteria were as follows: pregnant women with serum creatinine $>0.9$ $\mathrm{mg} / \mathrm{dl}$, oligohydramnios, chorioamnionitis, chromosomal abnormalities, congenital defects, use of nephrotoxic drugs during pregnancy, pregnant women with unreliable gestational age, hypertension or diabetes, and $\mathrm{Rh}$-sensitized and pregnant women who had a cesarean section for newborns with fetal distress or Apgar score below 7 in the first minute. If subsequent cytogenetic study presented any anomaly, patients were also excluded. Maternal blood was drawn by venipuncture without anticoagulants at the same time as the amniotic fluid sample. All amniocenteses were performed by the transabdominal route using a 22-gauge spinal needle or during a cesarean section after hysterotomy, with removal of approximately 10 to $20 \mathrm{ml}$ of amniotic fluid. Samples containing blood or meconium were discarded. Amniotic fluid and maternal blood samples were stored at $-20^{\circ} \mathrm{C}$ if not analyzed on the same day and a reading was carried out within two weeks at the Biochemistry and Radioimmunoassay Laboratories of Hospital de Clínicas de Porto Alegre.

Creatinine, NAG, B2-microglobulin, glucose, sodium, potassium, urea, phosphorus, calcium, uric acid and albumin concentrations, and osmolality were determined in amniotic fluid and maternal serum. Some samples of amniotic fluid were too small to analyze all markers. Creatinine, urea, uric acid, calcium, glucose, phosphorus and albumin are reported as $\mathrm{mg} / \mathrm{dl}$, osmolality as $\mathrm{mOsm} / \mathrm{l}$, and sodium and potassium as $\mathrm{mEq} / \mathrm{l}$.

Creatinine, urea, uric acid, glucose, calcium, phosphorus, albumin and osmolality were all determined with an automatic analyzer ("Mega Kits Merck Diagnostic"). NAG analysis was performed in Ul/min by colorimetry using substrates such as 4-phenyl-Nacetyl-glucosamine and nitrate buffer. B2Microglobulin was determined by the Immulite technique and is reported as $\mathrm{ng} / \mathrm{ml}$.

The study was approved by the Ethics 
Committee of Hospital de Clínicas de Porto Alegre. All samples were obtained after the patients were informed about the potential risks and the objectives of the study and gave written consent to participate.

\section{Statistical analysis}

A data base was created using the EpiInfo 6.04 program (CDC, Atlanta, GA, USA). Statistical analysis was carried out using the SPSS 8 program. All data are reported as means \pm SD and range of measured levels. Differences in mean concentrations of the variables among the three selected amniotic fluid periods were analyzed by one-way analysis of variance (ANOVA). Nonparametric Kruskal-Wallis tests were applied when variable distribution did not adjust to the normal curve. The Duncan test was used when ANOVA or Kruskal-Wallis identified any difference among the three gestational periods. We used a formula based on a 95\% confidence interval and standard error to determine the normal values of the results. Linear regression analysis and Pearson's or Spearman's correlation coefficient (r) were used to determine significant relationships between the biochemical variables. Statistical significance was established at $\mathrm{P}<0.05$.

\section{Results}

For a total of 115 pregnant women included in the study, 37 samples (32.2\%) were obtained during the first period (13-20 weeks), 18 (15.5\%) during the second (2734 weeks) and $60(52.2 \%)$ during the third (36-42 weeks). During the first period the mean age of the pregnant women was 34 years, significantly higher $(\mathrm{P}<0.05)$ than the second (27 years) and the third (26 years). All biochemical markers studied showed a significant difference at least between two of three gestational periods when we applied ANOVA or the Kruskal-Wallis test. The Duncan test was used to determine differences.

Table 1 shows the values of the biochemical markers throughout gestation. Creatinine was significantly increased throughout gestation $(\mathrm{P}<0.01)$. This increase was also demonstrated by urea, potassium and uric acid $(\mathrm{P}<0.01)$. NAG showed a signifi-

Table 1. Values of biochemical markers in amniotic fluid throughout gestation.

\begin{tabular}{|c|c|c|c|c|c|}
\hline Biochemical markers & $\begin{array}{c}\text { Group } 1 \\
\text { (13-20 weeks) }\end{array}$ & $\begin{array}{c}\text { Group } 2 \\
\text { (27-34 weeks) }\end{array}$ & $\begin{array}{c}\text { Group } 3 \\
\text { (36-42 weeks) }\end{array}$ & $\mathrm{F}$ & $P$ \\
\hline Creatinine (mg/dl) & $0.60 \pm 0.07^{a, b}$ & $1.28 \pm 0.34^{c}$ & $1.83 \pm 0.42$ & 140.21 & 0.000 \\
\hline NAG (Ul/min) & $14.56 \pm 1.18^{\mathrm{b}}$ & $20.62 \pm 11.75$ & $27.32 \pm 17.57$ & 7.58 & 0.000 \\
\hline B2-Microglobulin (ng/ml) & $8.10 \pm 3.34^{a, b}$ & $5.12 \pm 2.32^{c}$ & $2.28 \pm 1.04$ & 66.88 & 0.000 \\
\hline Glucose $(\mathrm{mg} / \mathrm{ml})$ & $46.88 \pm 13.57^{a, b}$ & $29.11 \pm 21.66 c$ & $17.94 \pm 13.53$ & 38.58 & 0.000 \\
\hline Urea (mg/dl) & $23.03 \pm 6.34^{a, b}$ & $29.41 \pm 7.12^{c}$ & $31.52 \pm 11.57$ & 8.22 & 0.000 \\
\hline Sodium (mEq/l) & $134.08 \pm 3.75^{b}$ & $128.35 \pm 5.47$ & $122.53 \pm 13.40$ & 14.03 & 0.000 \\
\hline Potassium (mEq/l) & $3.79 \pm 0.52^{a, b}$ & $4.25 \pm 0.42^{c}$ & $4.62 \pm 0.82$ & 15.30 & 0.000 \\
\hline Osmolality (mOsm/l) & $264.81 \pm 9.54^{b}$ & $259.62 \pm 15.34$ & $237.54 \pm 31.42$ & 14.22 & 0.000 \\
\hline Phosphorus (mg/dl) & $3.09 \pm 1.10^{\mathrm{a}, \mathrm{b}}$ & $1.44 \pm 0.61$ & $1.83 \pm 0.81$ & 24.48 & 0.000 \\
\hline Calcium (mg/dl) & $6.68 \pm 0.95^{b}$ & $6.31 \pm 1.03$ & $6.04 \pm 0.95$ & 4.71 & 0.011 \\
\hline Uric acid (mg/dl) & $3.11 \pm 1.07^{a, b}$ & $5.45 \pm 2.43^{c}$ & $7.64 \pm 1.59$ & 80.36 & 0.000 \\
\hline Albumin (mg/dl) & $0.35 \pm 0.12^{b}$ & $0.28 \pm 0.16$ & $0.23 \pm 0.14$ & 14.22 & 0.001 \\
\hline
\end{tabular}

Results are reported as mean \pm SD. Data were analyzed by ANOVA and the Kruskal-Wallis test. Multiple comparisons were made using the Duncan test $(\mathrm{F})$. NAG $=\mathrm{N}$-acetyl-ßS-D-glucosaminidase.

ap $<0.01$, group 1 vs group 2 .

bP $<0.01$, group 1 vs group 3 .

CP $<0.01$, group 2 vs group 3 . 
cantly increase only between the first and third period. On the other hand, B2-microglobulin and glucose demonstrated significant decreases throughout pregnancy $(\mathrm{P}<0.01)$. Sodium, calcium, albumin and osmolality showed a significant $(\mathrm{P}<0.01)$ decrease only between the first and third period. Phosphorus showed a significantly de-

Table 2. Pearson's correlation coefficient between creatinine and gestational age and biochemical markers in amniotic fluid.

\begin{tabular}{lrc}
\hline & Gestational age & Creatinine \\
\hline Creatinine & $r=0.85$ & - \\
NAG & $r=0.39$ & $r=0.26$ \\
B2-Microglobulin & $r=-0.73$ & $r=-0.68$ \\
Glucose & $r=-0.65$ & $r=-0.60$ \\
Urea & $r=0.36$ & $r=0.54$ \\
Sodium & $r=-0.46$ & $r=-0.26$ \\
Potassium & $r=0.49$ & $r=0.62$ \\
Phosphorus & $r=-0.51$ & $r=-0.39$ \\
Calcium & $r=-0.27$ & $r=-0.14$ \\
Uric acid & $r=0.78$ & $r=0.80$ \\
Albumin & $r=-0.37$ & $r=-0.29$ \\
Osmolality & $r=-0.45$ & $r=-0.31$ \\
\hline
\end{tabular}

NAG $=\mathrm{N}$-acetyl-ßS-D-glucosaminidase.

$\mathrm{P}=0.00$ for all cases. creasing growth profile between the first and third period and a nonsignificant increase between the second and third period.

Table 2 shows Pearson's correlation coefficient between creatinine and gestational age and biochemical markers. We observed significant correlations $(r>0.6)$ between gestational age and creatinine $(\mathrm{r}>0.85, \mathrm{P}<0.01)$, B2-microglobulin $(r>-0.73, \mathrm{P}<0.01)$, glucose $(\mathrm{r}>-0.65, \mathrm{P}<0.01)$, and uric acid $(\mathrm{r}>0.78$, $\mathrm{P}<0.01)$.

We also observed significant correlations between creatinine and $B 2$-microglobulin $(r>-0.68, P<0.01)$, uric acid $(r>0.80, P<0.01)$, glucose $(r>-0.60, P<0.01)$, potassium $(r>0.62$, $\mathrm{P}<0.01)$ and urea $(r>0.54, \mathrm{P}<0.01)$. Significant correlations were also observed between sodium and osmolality $(r>0.63, \mathrm{P}<0.01)$ and between uric acid and 32 -microglobulin $(\mathrm{r}>-0.61, \mathrm{P}<0.01)$.

Figure $1 \mathrm{~A}$ to $1 \mathrm{E}$ shows the profile of creatinine, NAG, B2-microglobulin, sodium and uric acid determined at the three time points throughout gestation.

The present study did not identify any influence of maternal age, race, parity, or
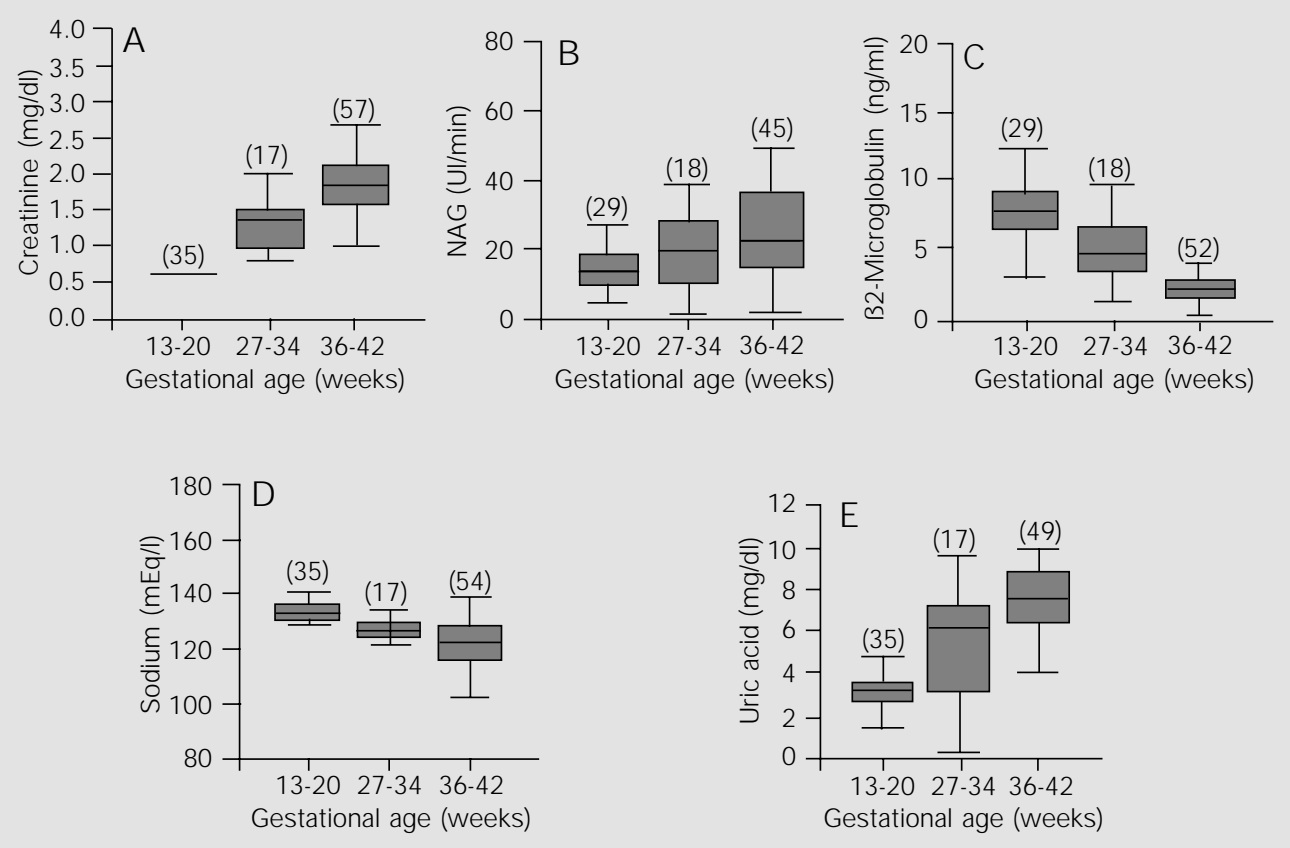

Figure 1. The amniotic fluid profile of creatinine, $\mathrm{N}$-acetyl-ß-Dglucosaminidase (NAG), ß2-microglobulin, sodium and uric acid at three time points during gestation. A, Creatinine $x$ gestational age. B, NAG $\times$ gestational age. C, B2-Microglobulin $x$ gestational age. $\mathrm{D}$, Sodium $\times$ gestational age. $E$, Uric acid $x$ gestational age. The total number of samples measured for each marker are given on the $x$ axis and the values found for each biochemical marker at the three gestational time points are given on the $y$ axis. The number of samples studied is given in parentheses. 
fetal sex on the results and maternal blood also did not show any influence on amniotic fluid parameters.

\section{Discussion}

The fetal kidneys start to develop during the 4th and 5th weeks of gestation and begin to excrete urine into the amniotic fluid at the 8 th to 11 th week $(15,16)$. At the 20 th week the fetal kidneys produce most of the amniotic fluid $(17,18)$. Therefore, important changes are expected in the composition of amniotic fluid as gestation progresses and fetal maturation occurs. As new diagnostic methods and new treatments advance the possibility to solve fetal anomalies, or as an improvement of quality of life becomes possible, the necessity arises for a multidisciplinary team to decide for the continuation or interruption of pregnancy.

Renal maturity is defined by the increase in glomerular filtration and by the maturity of renal tubular cells that begin to express various tubular transporters over the months of gestation (9,19-21). Glomerular filtration in the fetal kidney can be assessed by the concentrations of creatinine and urea in the amniotic fluid (12). The evaluation of renal maturity can also indicate fetal maturity $(17,18)$. In non-pregnant women, creatinine, urea, NAG, B2-microglobulin and other biochemical markers are used to evaluate the complex functioning of human kidneys. In the first half of pregnancy, creatinine concentrations are similar in maternal serum and in amniotic fluid (17).

Pregnant women in the first gestational group had a mean creatinine concentration of $0.6 \mathrm{mg} / \mathrm{dl}$ in the amniotic fluid, similar to that found in maternal serum.

Creatinine concentrations in amniotic fluid increased gradually between 20 to 32 weeks of gestation and more rapidly thereafter, when they were two to four times higher than in maternal serum $(9,22,23)$. Creatinine concentrations of $2 \mathrm{mg} / \mathrm{dl}$ represent an age of at least 37 weeks of gestation (24). We observed an increase in creatinine and urea in the third trimester. It seems evident that the origin of these two markers is a function of filtration in the fetal kidneys. Creatinine demonstrated a significantly increasing growth profile throughout pregnancy as determined at all three gestational times. Creatinine values from 36 weeks of gestation (1.72-1.95 $\mathrm{mg} / \mathrm{dl}$ ) fully agreed with data reported in other articles, which confirmed renal maturation (11). The increasing growth profile of creatinine and urea throughout normal pregnancy is due to glomerular filtration and maturation of tubular function.

The function of the renal tubule system, specifically proximal tubules, can also be assessed by the concentrations of 32 -microglobulin and NAG in the third trimester of gestation $(1,25)$. B2-Microglobulin is a light chain polypeptide of the HLA class I antigen complex. It was first isolated in 1968 from the urine of patients with Wilson's disease and cadmium poisoning. Its function is unknown, but this protein may control the expression and biosynthesis of antigens on the cell surface. Because of its low molecular weight, $99 \%$ of all free 32 -microglobulin is rapidly eliminated by glomerular filtration $(26,27)$.

In primary diseases of renal tubules, where tubular damage and tubular acidosis occur, the urinary excretion of B2-microglobulin can increase due to a reduced reabsorption of this molecule $(22,28)$. Fetuses produce B2-microglobulin, with serum levels being detectable from the 11th week of gestation. B2-Microglobulin produced by the fetus is filtered and reabsorbed by proximal tubules, with an expected reduction in its concentrations at week 36 in normal pregnancies. This reduction can be considered as an index of renal tubular maturation $(22,28)$.

B2-Microglobulin showed a significantly decreasing growth profile $(\mathrm{P}<0.05)$, as previously reported by Zimmerhackl et al. (29). Theories can explain it as a reduced transfer 
of maternal blood, a dilution mechanism or reduced production in the third trimester but there is no proven theory (30). B2-Microglobulin showed a good correlation with levels of creatinine, uric acid and gestational age, suggesting its importance as a renal marker.

NAG is a high molecular weight lysosomal enzyme present in renal tubular cells $(1,31)$. The excretion rate is not affected by serum concentrations since NAG is not filtered by the glomeruli. Increased NAG values are found in various renal diseases and therefore can reflect renal damage (27).

In our study, NAG showed a significantly increasing growth profile between the first and third gestational groups. The higher values in later stages of pregnancy could reflect fetal growth and the greater mass of fetal kidneys (27).

Our results showed a decreasing glucose growth profile throughout gestation. This decreasing profile and a good correlation with creatinine and gestational age suggest that glucose is a good indicator of renal maturation. Sodium reabsorption by the fetal kidneys at the end of pregnancy is about 85 to $95 \%$ of the filtered load. Therefore, the fetal urine is usually hypotonic compared to plasma, indicating very efficient reabsorption capacity in the collecting duct $(32,33)$. Our results are compatible with a larger reabsorption of sodium and lower concentrations in the amniotic fluid in the third trimester of pregnancy, as already demonstrated by other authors $(15,34)$.

It was also possible to demonstrate lower concentrations of osmolality in the amniotic fluid in the third trimester of gestation and a good correlation between sodium and osmolality which would be expected due to their close physiologic relationship.

Almost complete development of the fetal kidneys with adequate functioning of all receptors that carry out transport in the renal cells would be expected to occur in the third trimester. For example, the Na-K-ATPase protein present in all tubular segments has a main role in sodium reabsorption. There is an increasing growth of this protein during renal development, which is also accompanied by a larger capacity of renal tubules to transport sodium and water $(32,33)$.

Potassium demonstrated a slightly increasing growth profile throughout gestation, confirming observations reported by Benzie et al. (24). These results are in accordance with the maturation of distal and collecting tubules that are responsible for potassium handling by the fetal kidneys $(20,35)$.

Uric acid presented higher concentrations at the end of gestation, similar to results reported by Bauk et al. (10). Calcium, phosphorus and albumin, all substances processed by different segments of the renal tubules, showed significant differences between the first and third gestational groups, in contrast to data reported by others (34). Osmolality was similar to the levels reported in the classic work of Mandelbaum and Evans in 1969 (36).

As gestation progresses, the fetal kidneys follow the same developmental principles as adult kidneys. In man, the basic histoarchitecture of the kidney has formed by 32 to 36 weeks of gestation, and no new nephric units form after this period (37).

Since creatinine represents the most accurate renal marker, we considered as good indicators of maturation and renal function all markers that presented Pearson's or Spearman's correlation coefficient greater than 0.6 with gestational age and creatinine simultaneously. The profile of biochemical markers throughout gestation regardless of correlation coefficients demonstrates the physiology of amniotic fluid as the fetal kidneys mature.

B2-Microglobulin, glucose and uric acid presented important correlations with creatinine and gestational age, which suggest that they are good indicators of renal development during gestation. Urea, potassium and phosphorus presented mild correlations, 
which suggest that they may be possible indicators of renal development during gestation. NAG showed a weak correlation with both, which suggests that this enzyme is not a good indicator of renal maturation. Similar results were obtained for sodium, calcium, albumin and osmolality.

The heterogeneity of our patients is a limitation of our study but for ethical reasons it was felt to be proper to obtain samples of amniotic fluid only when there was a medical indication for this procedure. Despite the reduced number of pregnant women in the second group (27 to 34 weeks), the statistical power of the data was good enough to analyze all our variables. This reduced number was due to all exclusion criteria used to select the patients.

Patients selected in the first period were significantly older (34 years) compared to the other two periods. This was expected because most of these patients had advanced maternal age as one of the indications for amniocentesis.

The precise mechanisms underlying structural, molecular and cellular aspects during nephrogenesis only recently have begun to be studied. The process of undifferentiated cells forming proximal tubules, loops of Henle, distal tubules, and collecting urinary system with the creation of a system for transportation of water and solutes is a vast field of investigation (15). There are a great deal of renal syndromes such as aplasia, hypoplasia, dysplasia, neoplasm and cystogenesis that result from abnormal nephrogenesis (38). Therefore, the study of fetal kidney development during embryogenesis as well as knowledge of the functioning of various cellular transporters during gestation can provide important information about the physiology and pathophysiology of many syndromes that occur during gestation.

\section{References}

1. Mussap M, Fanos V \& Piccoli A (1996). Low molecular mass proteins and urinary enzymes in amniotic fluid of healthy pregnant women at progressive stages of gestation. Clinical Biochemistry, 29: 51-56.

2. Seeds AE (1980). Current concepts on amniotic fluid dynamics. American J ournal of Obstetrics and Gynecology, 1: 1116.

3. Lettgen B, Meyer-Schwickerath $M \&$ Bedow W (1993). Die antenatale Ultraschalldiagnostik der Nieren und der ableitenden Harnwege. Monatsschrift für Kinderheilkunde, 141: 462-467.

4. Grupe WE (1987). The dilemma of intrauterine diagnosis of congenital renal disease. Pediatric Clinics of North America, 34: 629-638.

5. Shackelford GP, Kees-Folts D \& Cole BR (1992). Imaging the urinary tract. Clinics in Perinatology, 19: 85-119.

6. Bailão LA, Cunha SP \& Martinez AR (1975). O valor da creatinina no líquido amniótico como índice de maturidade fetal. J ornal Brasileiro de Ginecologia, 79: 247-249.

7. Liu-Y \& Gong-GL (1982). Clinical observa- tion of amniotic fluid creatinine as an index of fetal maturity. Chinese Medical J ournal (English), 95: 697-702.

8. Pitkin RM \& Zwirek SJ (1967). Amniotic fluid creatinine. American J ournal of Obstetrics and Gynecology, 98: 1135-1139.

9. Tyden O, Eriksson U \& Agren H (1983). Estimation of fetal maturity by amniotic fluid cytology, creatinine, lecithin/sphingomyelin ratio and phosphatidylglycerol. Gynecologic and Obstetric Investigation, 16: 317-326.

10. Bauk FA, Moron AF \& Novo Y (1996). Estudo comparativo das dosagens de sódio, potássio, uréia, creatinina e ácido úrico no líquido amniótico entre 15-20 semanas e 38-42 semanas. Revista da Associação Médica Brasileira, 42: 7-10.

11. Deshpande TV, Harding PG \& J aco NT (1977). Estimation of gestational age from study of amniotic fluid and clinical assessment. Canadian Medical Association J ournal, 117: 886-890.

12. Ring $E$, Hofmann $H \&$ Enwa $W$ (1991). Amniotic fluid $\mathrm{N}$-acetyl-ßB-D-glucosaminidase activity and renal abnormalities. Archives of Disease in Childhood, 66: 1147-
1149.

13. Shardijin G \& Statius van Epps L (1987). B2-Microglobulin: its significance in the evaluation of renal function. Kidney International, 32: 635-641.

14. Harrison MR \& Filly RA (1990). The fetus with obstructive uropathy: Pathophysiology, natural history, selection, and treatment. In: Harrison MR, Golbus MS \& Filly RA (Editors), The Unbom Patient: Prenatal Diagnosis and Treatment. 2nd edn. W.B. Saunders, Philadelphia, PA, USA, 328-393.

15. Brenner BM (1990). Determinant of differentiation during early nephrogenesis. J ournal of the American Society of Nephrology, 1: 127-130.

16. Nigam SK, Aperia AC \& Brenner BM (1996). Development and maturation of the kidney. In: Brenner BM (Editor), The Kidney. 5th edn. W.B. Saunders, Philadelphia, PA, USA.

17. Hennemann CE, Andersson GV \& Tejavey A (1970). Fetal maturation and amniotic fluid. American J oumal of Obstetrics and Gynecology, 108: 302-307.

18. Lumbers ER (1984). A brief review of fe- 
tal renal function. J oumal of Developmental Physiology, 6: 1-10.

19. Delpire E, Rauchman MI \& Beier DR (1994). Molecular cloning and chromosome localization of a putative basolateral $\mathrm{Na}-\mathrm{K}-2 \mathrm{Cl}$ co-transporter from mouse inner medullary collecting duct (mIMCD-3) cells. J oumal of Biological Chemistry, 269: 25677-25683.

20. Gamba G, Miyanoshita A \& Lombardi M (1994). Molecular cloning, primary structure, and characterization of two members of the mammalian electroneutral sodium-(potassium)-chloride co-transporter family expressed in kidney. J oumal of Biological Chemistry, 269: 17713-17722.

21. Imbert-Teboul $M$, Chabardes $D \&$ Clique A (1984). Ontogenesis of hormone-dependent adenylate cyclase in isolated rat nephron segments. American J ournal of Physiology, 247: 316-325.

22. Cruikshank DP (1982). Amniocentesis for determination of fetal maturity. Clinical Obstetrics and Gynecology, 25: 773-785.

23. Raghav $M$, Vijay $G \&$ Chowdhary $D R$ (1985). Amniotic fluid amino acids, urea, creatinine in normal and toxemic pregnancies. Indian J ournal of Medical Sciences, 39: 291-293.

24. Benzie RJ , Doran TA \& Harkins J L (1973). Composition of the amniotic fluid and matemal serum in pregnancy. American
J ournal of Obstetrics and Gynecology, 119: 798-810.

25. Puolaka J, Ylostalo P \& Tuimala R (1982). Amniotic fluid beta2-microglobulin in normal and complicated pregnancies. Gynecologic and Obstetric Investigation, 13: 129-134.

26. Backman L, Ringden O \& Bjorkhem I (1986). Increased serum ß2-M during rejection cyclosporin-induced nephrotoxicity and cytomegalovirus infection in renal transplant recipients. Transplantation, 42: 368-371.

27. Cobet $G$, Gummelt $T \&$ \& Bollmann $C$ (1996). Assessment of serum levels of alfa microglobulin, B2 microglobulin, and retinol binding protein in the fetal blood. A method for prenatal evaluation of renal function. Prenatal Diagnosis, 16: 299-305.

28. Strassner HT \& Nochimson DJ (1982). Determination of fetal maturity. Clinics in Perinatology, 9: 297-312.

29. Zimmerhackl LB, Rostasy K \& Wiegele G (1996). Tamm Horsfall protein as a marker of tubular maturation. Pediatric Nephrology, 10: 448-452.

30. Padovani EM, Fanos $V \& \&$ Mussao $M$ (1994). Tubular proteins and enzyme content in the amniotic fluid. European J ournal of Obstetrics Gynecology and Reproductive Biology, 55: 129-133.

31. Marhun D (1976). Rapid colorimetric as- say of ß-galactosidase and N-acetyl-ß-glucosaminidase in human urine. Clinica Chimica Acta, 73: 453-461.

32. Robillard J E, Matson JR \& Sessions C (1979). Developmental aspects of renal tubular reabsorption of water in the lamb fetus. Pediatric Research, 13: 1172-1176.

33. Robillard JE, Nakamura KT \& Matheme GP (1988). Renal hemodynamics and functional adjustments to postnatal life. Seminars in Perinatology, 12: 143-150.

34. Daffos $F \&$ Forestier $F$ (1988). Médicine et Biologie du Foetus Humain. Maloine, Paris, France.

35. Satlin LM (1991). Maturation of renal potassium transport. Pediatric Nephrology, 5: 260-269.

36. Mandelbaum B \& Evans TN (1969). Life in the amniotic fluid. American J oumal of Obstetrics and Gynecology, 104: 365-377.

37. Ekblom P (1994). Embryology and prenatal development. In: Holliday MA, Barratt TM \& Avner ED (Editors), Pediatric Nephrology. 3rd edn. Williams and Wilkins, Baltimore, MD, USA.

38. Nicolini U, Fisk NM \& Rodeck CH (1992). Fetal urine biochemistry: an index of renal maturation and dysfunction. British J ournal of Obstetrics and Gynaecology, 99: 46-50. 